\title{
Respiratory Sleep Disturbances in Patients Undergoing Gastric Bypass Surgery and Their Relation to Metabolic Syndrome
}

\author{
Neus Salord $\cdot$ Mercedes Mayos $\cdot$ Rosa Miralda \\ Antonio Perez
}

Published online: 14 May 2009

(C) Springer Science + Business Media, LLC 2009

\section{Erratum to: OBES SURG \\ DOI 10.1007/s11695-008-9670-0}

The first author has informed the Journal that he inadvertently provided an incorrect citation for his affiliation in the original publication. The affiliation citation should have read: Hospital de la Santa Creu i Sant Pau and the Medicine Department of the Universitat Autonoma de Barcelona.

The online version of the original article can be found at http://dx.doi. org/10.1007/s11695-008-9670-0.

N. Salord $(\bowtie) \cdot$ M. Mayos $\cdot$ R. Miralda

Hospital de la Santa Creu i Sant Pau and the Medicine

Department of the Universitat Autonoma de Barcelona,

Sant Antoni Maria Claret 167,

08025 Barcelona, Spain

e-mail: nsalord@csub.scs.es

\section{A. Perez}

Department of Endocrinology,

Hospital de la Santa Creu i Sant pau,

Barcelona, Spain 